\title{
Partitioning Behavior of Gemifloxacin in Anionic, Cationic and Nonanionic Surfactants. Calculation of Dermal Permeability Coefficient
}

\author{
Theophilus C. Onyekaba1', Chukwudinma C. Achilefu², Chika J. Mbah" ${ }^{2 *}$ \\ ${ }^{1}$ Department of Pharmaceutical Chemistry, Faculty of Pharmaceutical Sciences, Delta State University, Abraka, \\ Nigeria \\ ${ }^{2}$ Department of Pharmaceutical and Medicinal Chemistry, Faculty of Pharmaceutical Sciences, University of \\ Nigeria, Nsukka, Nigeria \\ Email: cjmbah123@yahoo.com
}

Received 27 January 2015; accepted 25 March 2015; published 26 March 2015

Copyright (C) 2015 by authors and Scientific Research Publishing Inc. This work is licensed under the Creative Commons Attribution International License (CC BY). http://creativecommons.org/licenses/by/4.0/

(c) (i) Open Access

\section{Abstract}

Transdermal delivery acts as an alternative to oral delivery of drugs and possibly provids also an alternative to hypodermic injection. Transdermal delivery when compared to oral route has a variety of advantages namely: avoiding the degradation of drugs in the stomach environment, providing steady plasma levels, avoiding first-pass metabolism, increaseing patient compliance, easy to use, non-invasive and inexpensive, increasing the therapeutic index with a simultaneous decrease in drug side effects. Despite these advantages, one of the greatest challenges to transdermal delivery is that only a limited number of drugs are amenable to administration by this route. Gemifloxacin, a broad spectrum fourth generation quinolone antibacterial agent has pharmacokinetic characteristics (particularly its low maximum plasma concentration, obtained following repeat oral dose of $320 \mathrm{mg}$ ) that makes it a potential target for transdermal delivery. The objective of the study was to explore the possibility of surfactants (anionic, cationic and nonionic) acting as dermal enhancers of gemifloxacin assuming that the drug is to be formulated into topical or transdermal pharmaceutical dosage form. To accomplish the objective, gemifloxacin was partitioned between chloroform and surfactants containing varying concentrations of sodium lauryl sulfate, cetyltrimethylammonium bromide, polysorbate- 20 and polysorbate- 80 . The data obtained were used to estimate the dermal permeability coefficient. The partitioning was carried out by shake flask method at room temperature. It was observed that all the surfactants decreased the partition behavior of gemifloxacin when compared to that of water alone. Sodium lauryl sulfate

${ }^{*}$ Corresponding author.

How to cite this paper: Onyekaba, T.C., Achilefu, C.C. and Mbah, C.J. (2015) Partitioning Behavior of Gemifloxacin in Anionic, Cationic and Nonanionic Surfactants. Calculation of Dermal Permeability Coefficient. Pharmacology \& Pharmacy, 6, 207-211. http://dx.doi.org/10.4236/pp.2015.64022 
produced the most decreasing partition effect at the highest concentration studied $(2 \% \mathrm{w} / \mathrm{v})$. The permeability coefficient $\left(K_{p}\right)$ was estimated from the partition coefficient data and the molecular weight of the drug. As permeability coefficient is an important descriptor for evaluating dermal absorption of drugs employed in clinical treatment of various dermal accessible ailments, the results of the study suggest that the investigated surfactants might not be potential transdermal enhancers of gemifloxacin.

\section{Keywords}

\section{Gemifloxacin, Surfactants, Partition Coefficient}

\section{Introduction}

Gemifloxacin, 7-[\{4Z\}-3-(Aminomethyl)-4-(methoxyimino)-1-pyrrolidinyl]-1-cyclopropyl-6-fluoro-4-oxo-1,4dihydro-1,8-naphthyridine-3-carboxylic acid, is a broad spectrum fourth generation quinolone antibacterial agent. Clinically, the drug is used to treat acute bacterial exacerbation of chronic bronchitis, mild to moderate pneumonia. Its mechanism of action involves the inhibition of DNA synthesis through the inhibition of DNA gyrase and topoisomerase IV, enzymes essential for bacterial growth [1] [2]. The pharmacokinetics of gemifloxacin indicates that the mean maximal plasma concentration $\left(\mathrm{C}_{\max }\right)$ is $1.61 \pm 0.51 \mu \mathrm{g} / \mathrm{ml}$ following repeat oral dose of $320 \mathrm{mg}$. It was therefore, envisaged that the dose could be significantly reduced while achieving the required maximum plasma concentration, if transdermal route is considered an alternative. Transdermal drug delivery has made many important contributions in disease therapies and the successful use of topical formulations depends on understanding the drug transport through the dermal barriers. The stratum corneum (the outermost layer of the epidermis, about 10 - 40 um thick) provides the most barrier to the absorption into the circulation of most drugs deposited on the skin surface [3] [4]. Surfactants (amphiphilic molecules composed of a hydrophilic moiety known as the head and a hydrophobic moiety known as the tail) have been reported to be drug carriers or dermal absorption enhancers [5]-[7]. Dermal absorption enhancers are often required in transdermal formulations to amongst other things reduce the drug dose and invariably the adverse effects of the drug. Partitioning of drug through biological membranes is responsible for the pharmacological activity of the drug [8] [9]. Partition coefficient has been reported to be a good descriptor in evaluating dermal absorption of compounds [10]. Another study has also reported that the rate of penetration into the skin (dermal absorption) can be quantitatively determined by use of the permeability coefficient [11] [12]. Other study has shown that dermal permeability coefficient depends on the partition coefficient and molecular weight of the compound [13]. Furthermore, dermal permeability coefficient has been found to be an easy parameter in evaluating the usage and effectiveness of topical drugs [14]. Against this background, the present study was aimed at investigating the dermal enhancement potentials of anionic, cationic and nonionic surfactants on gemifloxacin by studying the partition characteristics of the drug in micellar solutions and using the data obtained to calculate the dermal permeability coefficient.

\section{Materials and Methods}

Gemifloxacin (Oscient Pharmaceuticals, USA), sodium lauryl sulfate, cetyltrimethylammonium bromide, polysorbate-20 and polysorbate-80 (Sigma-Aldrich, USA), chloroform (Fisher Scientific, USA) and other chemicals were of analytical grade.

\subsection{Standard Solution}

The stock solution of gemifloxacin $(10 \mu \mathrm{g} / \mathrm{ml})$ was prepared in methanol. Aliquots $(1.0-6.0 \mu \mathrm{g} / \mathrm{ml})$ of the standard stock solution were pipette into a $10 \mathrm{ml}$ volumetric flask and diluted to volume with methanol.

\subsection{Partition Coefficient Measurement}

The chloroform/water partition coefficient was measured by a shake-flask method [15]. To $5 \mathrm{ml}$ of chloroform 
(saturated with different micellar solutions) containing $100 \mu \mathrm{g}$ of gemifloxacin was added $5 \mathrm{ml}$ of aqueous micellar solution (saturated with chloroform). The flasks were capped and agitated at room temperature for $2 \mathrm{~h}$ to achieve complete equilibration. After that, the aqueous phases were separated and the concentrations were determined by measuring the UV absorbance at a maximum wavelength of $265 \mathrm{~nm}$. The partition coefficient of gemifloxacin was calculated using this equation [16]

$$
\mathrm{P}=\frac{\left(\mathrm{C}_{1}-\mathrm{C}_{\mathrm{w}}\right) \mathrm{V}_{\mathrm{w}}}{\mathrm{C}_{\mathrm{w}} \mathrm{V}_{\mathrm{o}}}
$$

where $\mathrm{P}=$ partition coefficient; $\mathrm{C}_{1}=$ total concentration of gemifloxacin; $\mathrm{C}_{\mathrm{w}}=$ concentration of gemifloxacin in aqueous phase; $\mathrm{V}_{\mathrm{w}}=$ volume of the aqueous phase; $\mathrm{V}_{\mathrm{o}}=$ volume of the organic phase.

\section{Results and Discussion}

The regression equation describing the Beer's plot of absorbance versus concentration of gemifloxacin reference standard is: $A=0.0685 C+0.0971\left(R^{2}=0.9998\right)$. The partition coefficient results of gemifloxacin are presented in Table 1.

The results show that all the surfactants used in the investigation decreased the partition coefficient of gemifloxacin. Sodium lauryl sulfate gave the most decreasing effect. For instance, at the highest concentration of surfactant $(2.0 \% \mathrm{w} / \mathrm{v})$ investigated, the logarithm of the partition coefficients of gemifloxacin are 1.904, 1.826, 1.812 and 1.770 for polysorbate-80, polysorbate-20, cetylmethylammonium bromide and sodium lauryl sulfate respectively. The overall decrease in the logarithm of partition coefficient of the drug at increasing surfactant concentrations could be due to the polar nature of the drug. For sodium lauryl sulfate, the decrease is probably associated more with alkaline $\mathrm{pH}$ of the surfactant solution (rather than micellar effect), which might have contributed to the ionization of the carboxylic acid group present in the drug, thus greater affinity the drug has for the aqueous phase than the organic phase. Ion association could be used more to explain the decreasing results observed with the cationic surfactant than the micellar effect. The positive charge on the cationic surfactant has the potential of forming ion pair with the primary amino group in the drug. However, for the nonionic surfactants, the decreasing effect is most likely to be due to the degree of entrapment of the drug in the micelles of the surfactant. The entrapment theory could be substantiated because it was observed that polysorbate- 80 showed more decreasing effect than polysorbate-20. The plots of logarithm partition coefficient versus concentration of the surfactant are shown in Figure 1. A decrease linear relationship was observed for each surfactant. The correlation coefficients are $-0.7785,-0.8711,-0.9472$ and -0.9350 for polysorbate- 80 , polysorbate- 20 , cetylmethylammonium bromide and sodium lauryl sulfate respectively.

In this investigation, only two molecular descriptors namely hydrophobicity (represented by log P) and molecule size (represented by molecular weight) were used to study the efficacy of predicting $K_{p}$ values. The results of the calculated permeability coefficients of gemifloxacin for various concentrations of the surfactants using the equation of Potts and Guy, are shown in Table 2.

Table 1. Effect of Sodium lauryl sulfate, Cetylmethylammonium bromide, Polysorbate-20 and Polysorbate-80 on the partition coefficient of Gemifloxacin.

\begin{tabular}{|c|c|c|c|c|}
\hline \multirow[t]{2}{*}{ Concentration of surfactant } & \multicolumn{4}{|c|}{ Logarithm Partition Coefficient of Gemifloxacin } \\
\hline & Sodium lauryl sulfate & $\begin{array}{c}\text { Cetylmethylammonium } \\
\text { bromide }\end{array}$ & Polysorbate-20 & Polysorbate-80 \\
\hline 0.00 & 2.283 & 2.283 & 2.283 & 2.283 \\
\hline 0.05 & 1.958 & 2.018 & 2.106 & 2.192 \\
\hline 0.10 & 1.936 & 1.980 & 2.042 & 2.096 \\
\hline 0.20 & 1.895 & 1.955 & 1.988 & 2.013 \\
\hline 0.50 & 1.861 & 1.912 & 1.948 & 1.963 \\
\hline 1.0 & 1.813 & 1.870 & 1.903 & 1.921 \\
\hline 2.0 & 1.770 & 1.812 & 1.826 & 1.904 \\
\hline
\end{tabular}




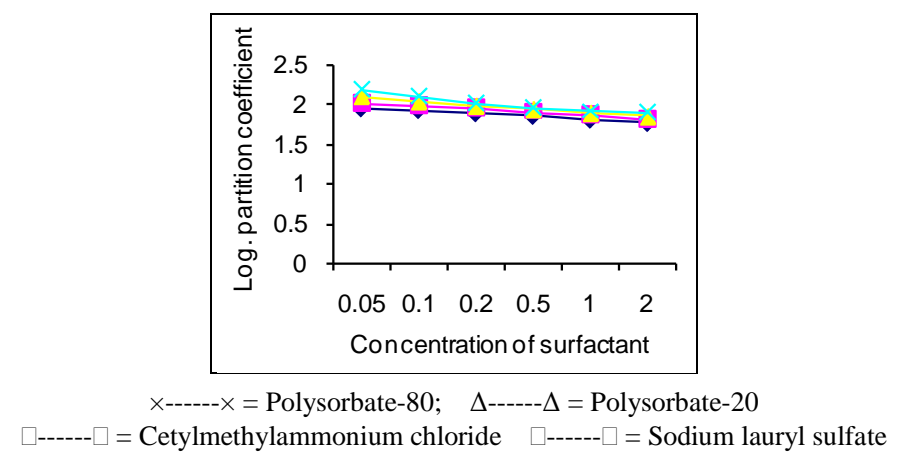

Figure 1. Plot of logarithm of partition coefficient of gemifloxacin versus concentration of surfactant.

Table 2. Effect of Sodium lauryl sulfate, Cetylmethylammonium bromide, Polysorbate-20 and Polysorbate-80 on the Permeability Coefficient of Gemifloxacin.

\begin{tabular}{crccc}
\hline Concentration of surfactant & \multicolumn{3}{c}{ Logarithm Partition Coefficient of Gemifloxacin } \\
\hline & Sodium lauryl sulfate & $\begin{array}{c}\text { Cetylmethylammonium } \\
\text { bromide }\end{array}$ & Polysorbate-20 & Polysorbate-80 \\
\hline 0.00 & -3.4743 & -3.4743 & -3.4743 & -3.4743 \\
0.05 & -3.7050 & -3.6624 & -3.5999 & -3.5389 \\
0.10 & -3.7206 & -3.6894 & -3.6454 & -3.6070 \\
0.20 & -3.7498 & -3.7072 & -3.6837 & -3.6660 \\
0.50 & -3.7741 & -3.7377 & -3.7121 & -3.7015 \\
1.0 & -3.8080 & -3.7675 & -3.7441 & -3.7050 \\
2.0 & -3.8385 & -3.8087 & -3.7987 & -3.7434 \\
\hline
\end{tabular}

The equation is: $\log \mathrm{K}_{\mathrm{p}}=-2.72+0.71 \log \mathrm{P}-0.0061 \mathrm{MW}$, where $\mathrm{K}_{\mathrm{p}}$ is the permeability coefficient, $\mathrm{P}$ is the partition coefficient and $\mathrm{MW}$ is the molecular weight of the compound. Potts and Guy equation, was used to predict (calculate) $K_{p}$ values because previous studies had demonstrated the equation to be a highly effective mathematical model for $\mathrm{K}_{\mathrm{p}}$ determination. However, in order to confirm the applicability of the equation to this investigation, the calculated logarithm of permeability coefficient of gemifloxacin was plotted against the logarithm of partition coefficient of the drug at one concentration level (2.0\% w/v) of the studied surfactants. Linear relationship was observed and regression equation defining the plot is $\log K_{p}=0.7098 \log P-1.0949\left(\mathrm{R}^{2}=\right.$ 0.9999).

\section{Conclusion}

The results suggest that the studied surfactants might not be potential transdermal enhancers of gemifloxacin. The investigation also suggests that the skin-vehicle partition coefficient may not be significantly affected, if any of the studied surfactants is found present in any dermal or topical formulation of gemifloxacin.

\section{References}

[1] Hooper, D.C. (2001) Emerging Mechanisms of Fluoroquinolones Resistance. Emerging Infectious Diseases, 7, 337341. http://dx.doi.org/10.3201/eid0702.010239

[2] Oliphant, C.M. and Green, G.M. (2002) Quinolones: A Comprehensive Review. American Family Physician, 65, 455464.

[3] Montagna, W., Van Scott, E.J. and Stoughton, R.B. (1972) Pharmacology and the Skin. Appleton Century Crafts, New York.

[4] Rutter, N. (1987) Drug Absorption through the Skin; a Mixed Blessing. Archives of Disease in Childhood, 62, $220-221$. 
http://dx.doi.org/10.1136/adc.62.3.220

[5] Hwang, C.C. and Danti, A.G. (1983) Percutaneous Absorption of Flufenamic Acid in Rabbits. Effect of Dimethylsulfoxide and Various Nonionic Surface Active Agents. Journal of Pharmaceutical Sciences, 72, 857-860. http://dx.doi.org/10.1002/jps.2600720805

[6] Shen, W.W., Danti, A.G. and Bruscato, F.N. (1976) Effect of Nonionic Surfactants on Percutaneous Absorption of Salicyclic Acid and Sodium Salicylate in the Presence of Dimethylsulfoxide. Journal of Pharmaceutical Sciences, 65, 1780-1783. http://dx.doi.org/10.1002/jps.2600651222

[7] Mbah, C.J. and Okekearu, L. (2013) Propylene Glycol, Polysorbate-80 and Sodium Lauryl Sulfate as Potential Dermal Absorption Enhancers of Celecoxib. Standard Scientific Research and Essays, 1, 32-35.

[8] Hansch, C. and Dunn III, W.J. (1972) Linear Relationships between Lipophilic Character and Biological Activity of Drugs. Journal of Pharmaceutical Sciences, 61, 1-19. http://dx.doi.org/10.1002/jps.2600610102

[9] Bawden, D., Gymer, G.E., Marriott, M.S. and Tute, M.S. (1984) Quantitative Structure-Activity Relationships in a Group of Imidazole Antimycotic Agents. The European Journal of Medicinal Chemistry, 18, 91-96.

[10] Bunge, A.L. and Cleek, R. L. (1995) A New Method for Estimating Dermal Absorption from Chemical Exposure. Effect of Molecular Weight and Octanol-Water Partitioning. Pharmaceutical Research, 12, 88-95. http://dx.doi.org/10.1023/A:1016242821610

[11] (1992) United States Environmental Protection Agency: Dermal Exposure Assessment: Principles and Applications. EPA/600/8-91/011 B.

[12] Karinth, S., Schaller, K.H. and Drexler, H. (2005) Is Permeability Coefficient $K_{p}$ a Reliable Tool in Percutaneous Absorption Studies. Archives of Toxicology, 79, 155-159. http://dx.doi.org/10.1007/s00204-004-0618-4

[13] Potts, R.V. and Guy, R.H. (1992) Predicting Skin Permeability. Pharmaceutical Research, 9, 663-669. http://dx.doi.org/10.1023/A:1015810312465

[14] Gennaro, A.R. (1995) Remington: The Science and Practice of Pharmacy. 19th Edition, Mack Publishing Company, Easton.

[15] Wang, F.A. (2001) Molecular Thermodynamics and Chromatographic Retention. China Meteorology Press, Beijing.

[16] Johansen, M. and Bundgaard, H. (1980) Prodrugs as Drug Delivery Systems XI. Solubility, Dissolution and Partition Behaviour of N-Mannich Bases and N-Hydroxymethyl Derivatives. Arch. Pharm. Chem. Sci. Edu., 8, 141-151. 